Res Pública Revista de Historia de las Ideas Políticas

ISSN: $1131-558 \mathrm{X}$

https://dx.doi.org/10.5209/rpub.75749

\title{
El republicanismo como terror femenino
}

\author{
Sol Peláez ${ }^{1}$
}

Recibido: 04-05-2021 / Aceptado: 16-09-2021

Resumen. Este ensayo lee Materialismo Salvaje de Jacques Lezra siguiendo la ética del terror que propone el autor en su pensamiento del republicanismo. Específicamente rastrea en el texto el terror del encuentro con la mujer. De acuerdo con Lezra, el concepto de Mujer es pivote para comprender cómo los conceptos (débiles) emergen. Repetidamente en su obra, el encuentro con la mujer corroe la fantasía del concepto fuerte y del soberano, y surge otra lógica republicana, no escatológica, no heroica, no sacrificial. Nos enfocaremos en el fracaso de la comunidad sadiana y en la emergencia de otra posible comunidad en María Zambrano. Así, este artículo propone una relectura feminista del trabajo de Lezra, rastreando el efecto corrosivo de la mujer en la construcción del concepto y concluye que la estructura de este evento republicano tal como lo piensa Lezra es femenina en términos de las fórmulas de sexuación de Jacques Lacan.

Palabras clave: República; terror; soberanía; feminismo; mujer; De Sade; Zambrano.

\section{[en] Republicanism as Feminine Terror}

Abstract. This essay reads Wild Materialism by Jacques Lezra following the ethics of terror that the author proposes in his thought of republicanism. Specifically, it traces the terror of the encounter with woman in the text. According to Lezra, the concept of Woman is pivotal to understand how the (weak) concepts emerge. Once and again in his work, the encounter with woman corrodes the fantasy of the strong concept and the sovereign and another logic arises, republican, non-scatological, non-heroic, and non-sacrificial. We will focus on the failure of the Sadean community and the emergence of another possible community in María Zambrano. Thus, this article proposes a feminist re-reading of Lezra's work, tracing the (un)work of woman in the construction of the concept and concludes that the structure of the republican event as thought by Lezra is feminine in terms of Jacques Lacan's sexuation formulas.

Keywords: Republic; Terror; Sovereignty; Feminism; Woman; De Sade; Zambrano.

Sumario. 1. Introducción: hacia una ética de lectura del fracaso. 2. La polis y el terror. 3. El terror, la mujer y los conceptos débiles. 4. Sade: Eugénie y su goce errante. 5. La madre y el veneno republicano. 6. Zambrano: la filosofía como mujer. 7. Aldonza y Dulcinea: estar, desprendimiento, e irradiación. 8. La derrota: Dulcinea y Don Quijote. 9. El terror del encuentro con Dulcinea/Aldonza/Zambrano. 10. El terror del encuentro y la lógica femenina. Bibliografía.

Cómo citar: Peláez, S. (2022). El republicanismo como terror femenino. Res Pública. Revista de Historia de las Ideas Políticas, 25(2), 75-85

\section{Introducción: hacia una ética de lectura del fracaso}

Materialismo Salvaje de Jacques Lezra nos invita a seguir la huella de las dudas del pensamiento, los momentos cuando el pensar vacila y se suspende inseguro hacia dónde ir, incitándonos a cultivar "una insecuritas sui" $[\mathrm{su} \text { inseguridad }]^{2}$. Lezra, el autor/texto, indaga en esos momentos de pausa cuando la lógica de la tradición logocéntrica titubea para así abrir una grieta en el pensamiento en sí y ofrecer una "vía divisoria, aleatoria" para pensar la soberanía y lo político ${ }^{3}$. Es una ética de lectura/ pensamiento que erosiona y explora, al tiempo que busca "provocar fallas", fracasos, divisiones, grietas y fisuras en los conceptos ${ }^{4}$. Leer a Lezra es entrar en un ritmo de pensamiento en el cual la lectura detallada cuestiona la palabra en su densidad material histórica. En ese tempo de la lectura, el texto muestra sus propias vacilaciones cuando se confronta con las diferentes fuentes que dan materialidad a su argumento y se cuestiona a sí mismo y a otros discursos, fuentes y pensadores. Este camino del terror en el pensamiento combina la argumentación más rigurosa con el relato y la historia para generar fracasos, fallas a través de las cuales reconsiderar los conceptos fundacionales de la modernidad como la soberanía, el

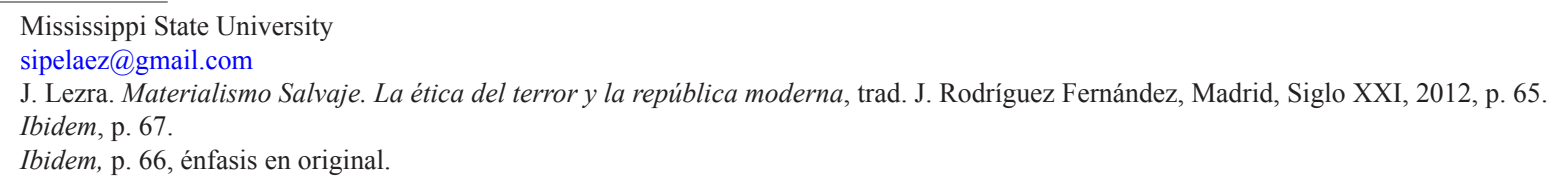


concepto y lo universal. Lezra nos invita, pues, al terror del pensar.

\section{La polis y el terror}

La ética de lectura de Lezra articula una pregunta fundamental que organiza la polis desde los tiempos de Edipo hasta los nuestros. Frente a un peligro inminente, $i^{\mathrm{a}}$ quién se debe sacrificar: al terrorista (contaminador) o a la ciudad? La fantasía de salvar la ciudad bajo la presión del tic-tac de la bomba y el sacrificio del terrorista funda desde siempre a la ciudad en la violencia hacia el otro, aquel que no pertenece. En contraste, el sacrificio de la herida y el exilio de Edipo soberano abren una alternativa. En su historia (y sus rescrituras), el soberano no es asesinado (al estilo del padre primordial freudiano de Totem y Tabú), sino que es simplemente herido (cegado) y forzado a dejar la polis. La imagen del soberano que puede sobrevivir herido, incapacitado, ciego, (sin poder ver, pero siendo visto) se convierte en la estallada fantasía fundacional de la comunidad. Mientras la primera respuesta (torturar al terrorista para salvar a la ciudad) mantiene la fantasía de una comunidad completa sin herida, la segunda incorpora la herida internamente (en el mismo movimiento de expulsarla). Frente a este contraste, Lezra se pregunta si es posible imaginar una comunidad "no escatológica, no heroica, no sacrificial"s. Figurar esto implica distanciarse de la polis y su decisión final (pero también fundacional) de protección contra la destrucción: torturar al extraño (el terrorista) que supuestamente conoce dónde se esconde la amenaza (la bomba y su tic-tac). La fantasía del peligro externo construye una muralla con un adentro y un afuera y una topología política de pertenencia-no pertenencia, derechos-no derechos, aceptación-rechazo, amigos-enemigos, amor-dolor, salvación-sacrificio y vida-muerte. Esta configuración política, argumenta Lezra, desde siempre implica una comunidad escatología, heroica y sacrificial. Construye un camino heroico al juicio final y la redención (o condena, pero toda condena implica la redención/purificación de la comunidad). Ese último juicio y sacrificio funciona en tanto la comunidad ha nacido en riesgo y se funda en actos preventivos y profilácticos que desde siempre están listos para (re)defenderla de su aniquilación mítica. La escena primordial catastrófica se constituye a sí misma en el escenario de la emergencia de la comunidad. La ruina está desde siempre antes de la comunidad a la que instaura. El juicio ético de la polis -qué hacer cuando la existencia de la polis está en juego- se encuentra desde siempre encerrado en una idea, un concepto, una fantasía que confina a la polis y libera la violencia terrorista contra el extranjero (siempre amenazador).

\section{El terror, la mujer y los conceptos débiles}

En contraposición a la polis sacrificante, Lezra propone un republicanismo radical moderno que no se base en un

Ibidem, p. 40. juicio ético (cómo lidiar con el extraño que es siempre peligroso) construido sobre una idea, un concepto o una fantasía suturante. El terror es el evento del encuentro con el otro; es ese afecto que no tiene objeto, que no se anticipa en su inminencia, y que para cuyo encuentro y experiencia una no estaba preparada. Una necesita aceptar estar abierta, ser abierta por el terror de la otra, aceptar la arbitrariedad de la otra, la cual puede interferir con una (y lo hará). Este encuentro implica terror porque no es previsible, pero acontece, y al suceder nos sorprende y muestra que no estábamos preparadas para el mismo. Al no poder prever el evento, es imposible hacer un juicio sobre él antes del mismo. No hay idea, concepto, que dé forma al encuentro previamente. No lo espero, pero sobreviene. $\mathrm{Y}$ aun si lo espero y me preparo (o sea tengo un plan, un juicio), el "encuentro" rompe estas expectativas y me toma por sorpresa. La contingencia del encuentro es el fondo de la república radical. El terror es el afecto de ese acontecimiento. Propongo leer Materialismo Salvaje siguiendo las huellas de ese evento, rastreando las suturas, las fallas, los fracasos y la apertura a la apertura a través de la figura de la mujer.

De acuerdo con Lezra, el concepto de "Mujer" es pivote para comprender cómo los conceptos modernos emergen:

La mujer es la figura culturalmente (material y contingentemente) disponible para que Hegel, Marx y Althusser representen el surgimiento del concepto porque la mujer (y no ya cualquier mujer, María es aquí el prototipo) incorpora una prioridad nuda, biológica, que se convierte en secundaria en el terreno de la cultura, una prioridad que se revela a sí misma como meramente simbólica ${ }^{6}$.

La mujer (particularizada en el caso de María) es usada por estos tres filósofos como la "escena primordial" de la emergencia del concepto7. La mujer se convierte en un concepto dialéctico que se eleva de lo particular a lo universal en el cual se subliman/ trascienden las diferencias. Una mujer (María) representa a todas; ella es la Mujer en tanto todas las Mujeres. Podemos observar acá la lógica falogocéntrica de la totalización, la lógica masculina de totalización de una estructura. María, como "inmaculada", autogenera el concepto de sí misma; se autoproduce en tanto concepto ${ }^{8}$. En tanto madre, ella se da luz a sí misma y da a luz al concepto y le enseña a reproducirse, a crear más conceptos, al tiempo que olvida el esfuerzo de la producción (la venida a la existencia) de la emergencia del concepto (que ya pertenecía a una estructura). Ella es, por lo tanto, totalmente exterior e interna a la estructura de los conceptos. Por eso, María cierra el sistema al tiempo que lo abre. El concepto nunca es autosuficiente; los filósofos cuentan el relato de María como una historia de autosuficiencia para borrar su debilidad. Así el concepto, analiza Lezra, sigue dos lógicas diferentes que se entremezclan en su emergencia: la filosófica y la literaria. La ficción literaria está allí para suturar, para cerrar el imposible cerco del concepto. El "concepto" de mujer usado en la filosofía

Ibidem, p. 226-227, énfasis en original.

Ibidem, p. 227.

Idem. 
logra tanto la sutura como al mismo tiempo interrumpe ese mismo concepto. Si la historia de la virgen María es fundante para la emergencia del concepto autocontenido (en tanto nunca puede autocontenerse) las lecturas de Lezra rastrean en otras figuras femeninas la emergencia de "conceptos débiles" y aterradores. Su argumento repetidamente trae a mujeres monstruosas, una ausente imagen de la reina Elizabeth analizada por el Padre Robert Pearson, Eugénie y su madre imaginadas por el Marqués de Sade, Thérèse y su suicidio en el film Kapo y las tres mujeres-bomba en La batalla de Alger de Gillo Pontecorvo o el análisis de Aldonza (y Dulcinea) en Cervantes (y el de España) de María Zambrano. Este trabajo propone una relectura feminista de Materialismo, siguiendo las huellas de la (in)operancia de las mujeres en la construcción del concepto débil de republicanismo específicamente en sus lecturas de Sade y Zambrano y la experiencia del terror.

Es importante notar la diferencia entre el terror y el terrorismo. El primero, como dijimos, marca el evento y el afecto del encuentro contingente con la otra/el otro. El segundo, es un uso instrumental, con arreglo a fines, calculado de la violencia sobre la otra/el otro. Uno es ético, el otro político. El primero nos abre y nos expone a la otra/el otro; el segundo nos cierra, nos protege en un acto profiláctico de la otra/del otro9. Para Lezra, "la distinción entre el terrorismo y el terror fundacional que custodia el republicanismo democrático radical" es "la condición de su forma ética, el concepto débil o la norma débil que se aloja en su seno"10. Este lenguaje nos lanza hacia el lado femenino: lo débil, el seno. Pareciera que, a primera vista, hubiera una diferencia entre un concepto fuerte (masculino) y otro débil (femenino). Los conceptos fuertes pertenecerían a la narrativa del logocentrismo y serían capaces de encapsular la variedad de la realidad y el pensamiento. Esta tradición reconoce en su centro a la cabeza, el pensamiento, la racionalidad y el logos. En contraste, Lezra propone un concepto débil que se encuentra en el seno del republicanismo. Debemos notar que esta lógica no sigue la distribución de roles tradicionales y fundados en una supuesta biología entre hombre y mujer, sino de lógicas que cierran o abren la posibilidad de pensar los conceptos de manera diferente. Así, el texto traza la lógica de una soberanía (imaginada como) indivisible a una soberanía divisible"11. La cuestión es seguir las huellas de esta gramática de lo débil, esta "ética del terror" 12 .

\footnotetext{
J. Lezra, República Salvaje: de la naturaleza de las cosas, Santiago de Chile, Macul, 2019, p. 301.

10 Lezra, Materialismo, op. cit. p. 109.

11 Ibidem, p. 141. Para Lezra, en el caso de la modernidad, la nueva experiencia del terror (o sea la contingencia del encuentro con la otra) fue pensada no a través de puros conceptos seculares o teológicos. En su análisis de una imagen ausente de la reina Isabel analizada por el Padre Robert Pearson en Newes from Spayne and Holland (1593), Lezra argumenta que la soberanía posee la misma topología que los conceptos débiles. En ese sentido, la soberanía es en el acto de suspensión que implica su propia división, y no en el acto de decisión. El contrato con la soberana siempre está sujeto a su contingencia histórica y a la "sobrelegibilidad" y "sublegibilidad", o sea, al exceso o falta en la lectura de sus condiciones, lo que implica la mala lectura, el abuso, la ceguera del contrato (la relación) entre soberano y súbitos/sujetos. Ibidem, 182. También cf. p. 138, 141, 142.

12 Ibidem, p. 110.
}

Los conceptos débiles poseen una topología paradójica por la cual el terror se expresa como su contenido. Los conceptos débiles tienen un valor normativo que se distancia del sujeto autónomo ético kantiano y la ley moral negativa normativa y prescriptiva, modifican las reglas de la asociación, reconocimiento e identidad y conecta la autonomía (en tanto asume un sujeto libre, ético haciendo y siguiendo las reglas) con la asociación $^{13}$. Existe en ellos una tensión entre autonomía y asociación, libertad y reglas, ética y política. Los conceptos débiles serían aquellos en los cuales la topología del adentro (contenido) y el afuera (lo que queda fuera del límite) no se sostiene. Por eso, el terror es parte del contenido de los conceptos débiles, porque erosiona los límites, la distinción entre contenido y límite, particular y universal ${ }^{14}$. Pero, como nota Lezra, "todos los conceptos son igualmente defectuosos y no defectuosos, todos, fuertes o no casi de la misma manera"15. Todos están sujetos al lenguaje y sus transacciones y sus condiciones históricas. El uso del lenguaje nunca es plenamente transparente. El concepto cruzado por la temporalidad emerge de la contingencia la cual se relaciona con las mismas reglas que producen los conceptos y que siempre pueden ser mal leídas, mal usadas, mal entendidas, abusadas, falseadas ${ }^{16}$. Así, siempre existe una contingencia que excede o falta en la lectura de los mismos ${ }^{17}$. La historicidad implica al mismo tiempo las condiciones necesarias y la contingencia y estructuras que son cerradas y abiertas. Esto no anula la diferencia entre terror y terrorismo, aunque los acerca. El concepto de terror se asume como débil (aunque puede eventualmente cerrarse), mientras que el de terrorismo busca la fortaleza, sutura activamente su debilidad, invisibilizándola, intentando anularla o contenerla (aunque fracase).

\section{Sade: Eugénie y su goce errante}

Para distanciarse de la lógica sacrificial del pensamiento político moderno, Lezra lee La filosofía en el tocador y observa en la comunidad sadiana la experiencia del terror republicano, "una versión fuerte de la contingencia ... [y una] crítica del heroísmo cultural [que] se configuran en una nueva pedagogía que se imagina previa" ${ }^{18}$. O sea, la comunidad sadiana sería una apertura al otro y a la contingencia del encuentro con el otro que no ofrece un manual didáctico (o sea normativo) para el futuro, sino que descarrila la educación. Frente a esta lectura, yo dudo. ¿Cuán lejos estamos de la imagen sacrificial y fundante que tortura al otro para protegerse? ¿Puede ser pensada la comunidad sadiana como una instancia de republicanismo radical, o sea, como "una alternativa a las lógicas instrumentales y fundacionales de asociación"19? La obra de Sade en todo lo que tiene de goce liberador continúa siendo fundante, sacrificial y profiláctica. Esto

\footnotetext{
Ibidem, p. 174 .

Ibidem, p. 175.

Idem.

Ibidem, p. 176.

Ibidem, p. 182.

Ibidem, p. 70-71.

$19 \quad$ Ibidem, p. 70.
} 
es en parte porque el pensamiento teológico del cual se quiere escapar todavía imprime su reverso en la forma de complicidad entre la mirada falologocéntrica patriarcal y el pensamiento político moderno. Sigue siendo una comunidad con amigos y enemigos, dominada por el pretendido soberano (padre o tutor). Siguiendo la ética de lectura de Lezra, argumento que la figura ciega de Eugénie y su goce errante nos abre a un nuevo republicanismo (siempre débil e incompleto) solo si nos enfocamos en su fracaso, su falla, en sus impases. Esto es si nosotros no nos dejamos cegar ante el dolor de la madre. Solo si miramos a las dos, al mismo tiempo, y consecutivamente, podemos pensar una apertura (fracasada) al concepto débil de republicanismo.

Los afectos y preguntas que La filosofía en el tocador de Sade han generado y todavía producen mantienen al pensamiento abierto, cambiante aún en el mismo lector. Este pareciera ser, por lo tanto, el texto ideal para la hermenéutica de la vacilación de Lezra. Como se sabe, la obra narra la metamorfosis, el "progreso" de Eugénie "una chica que solo ha perdido su virginidad" ese día, en una libertina "incestuosa, adultera, sodomita" ${ }^{20}$. Esta transfiguración se intercala con discusiones filosóficas sobre la República francesa, la Ilustración, la ley moral y las leyes de la naturaleza. La teoría y cuerpo se entrelazan elevando las leyes de la naturaleza por sobre las humanas, liberando el cuerpo y la moral de las imposiciones sociales. Al final de su capítulo sobre el texto de Sade, luego de hacer un racconto de las tribulaciones del texto (su escritura e interpretaciones), la lectura de Lezra congrega a dos mujeres y un hombre y resalta su con-tacto. Madame de Mistival está siendo suturada por Eugénie, su hija, quien está siendo acariciada/penetrada por atrás por Chevalier. La primera está siendo enviada al origen de una virginidad cerrada y podrida, la segunda está perdiéndose en el paroxismo de su placer mientras está teniendo sexo no reproductivo con un hombre que simplemente es acá un instrumento de ese placer. Las puntadas, Dolmancé ordena, deben "multiplicarse... así el cierre será lo suficientemente sólido" 21 . Pero, éstas parecieran perder dirección bajo el placer de Eugénie y "van a todos lados" y la "aguja deambula... a los muslos, a las tetas" "22. La aguja, el medio de tortura y sutura, pierde dirección en el goce de la hija y pareciera errar entre los tres cuerpos. Lezra observa: "Eugénie da puntadas a ciegas, no sólo creando una comunidad sin forja y des-obrada a partir de su placer violento, ciego, sino asimismo cambiando de generación, asumiendo el papel de Mistival y convirtiéndose en la institutriz de su madre" ${ }^{23}$. Por un lado, la ceguera de Eugénie señala la falla en el control y dominio y marca la división en la supuesta soberana. Sin la mirada, se extravía la dirección, o sea la racionalidad y la decisión. Esa mano ciega es "la forma más literal, material de contingencia" y revela la emergencia de una comunidad des-obrada, sin forma

\footnotetext{
M. de Sade, Justine, Philosophy in the Bedroom \& other Writings, comp. y trad. R. Seaver y A. Wainhouse, New York, Grove Press, 1990, p. 359, traducción propia.

21 Sade, op. cit., p. 365

22 Ibidem, p. 365, elipses en el original.

23 J. Lezra, Materialismo, op. cit., p. 259.
}

prescriptiva 24 . La aguja, en "el ciego errar de la mano de Eugénie" gana "una personalidad espectral propia" 25. Así la aguja es, "instrumento impersonal" a la vez que "personificación de la errática capacidad de actuar del placer" 26 . En tanto instrumento (objeto) y personificación del errar del placer (sujeto), la aguja conceptualiza débilmente la contingencia (el terror) del encuentro. La contingencia radical, que es violenta, permite en esta lectura la emergencia de una comunidad inesperada, congregando a la hija/torturadora, a la madre/víctima, al instrumento/penetrador (y a nosotros lectores/as). Lezra (y nosotros con él) mira ese cuerpo tripartito que en su con-tacto se une a través de la errancia de la aguja al sujeto, el objeto y el instrumento. Mantener la contingencia de este acoplamiento en tensión es parte de la reflexión republicana. Si la tortura de Madame de Mistival y la crueldad del placer de Eugénie deshacen el mundo de la madre, el placer violento y ciego de Eugénie deshace el suyo. Por el otro lado, la contingencia radical de las puntadas no se puede contener en una pedagogía, o sea, en un camino hacia la iluminación que enseña lo que vendrá. La hija toma el lugar de la madre, y viceversa. El camino fortuito de la aguja marca la contingencia de la emergencia de la comunidad, en tanto es un acontecimiento y en tanto genera terror.

Lezra ha seguido las huellas del terror de la emancipación (de Eugénie, de todas las hijas) y sus tensiones y mira con detenimiento "esta angustiosa -atrozescena"27. Rastrea cómo la tortura de la madre -esto es el castigo al origen- es hecha bajo un doble principio: el patriarcal y el libertino. Todo lo que le sucede al cuerpo de la madre está bajo la autoridad del esposo, Monsieur de Mistival quien es un estricto esposo y uno de los mejores libertinos, al decir de Dolmancé. De hecho, la madre ha sido siempre sólo la representante de la ley (su marido). Monsieur de Mistival, en tanto libertino, sostiene tanto las ideas del movimiento libertino -que proclama que los cuerpos pertenecen a nadie más que a la naturaleza y que el placer debe afirmarse- y en tanto esposo las ideas patriarcales -y posee el cuerpo de $s u$ mujer. El fundamento, por lo tanto, está cimentado en la ley falocéntrica patriarcal. La hija y aprendiz ahora es la extensión de la autoridad del padre (en su doble lógica: patriarcal falocéntrica -dueño de su esposa- y libertina-gozador del cuerpo del otro). El libertinaje impone una nueva ley kantiana: el tocar a la otra, pero esta ley se funda en la excepción: la madre puede ser tocada pero nunca tocar ${ }^{28}$. La sutura de la madre es el retorno a un origen antes del origen, un momento antes de ser madre. Este cierre es en sí mismo una nueva génesis, la emancipación de la hija. El nuevo origen se basa en el sacrificio del viejo origen. Alegórica y materialmente ahora el inicio del origen está podrido y condenado a la muerte mientras que el goce de la hija provee otro comienzo. El viejo sistema, entonces moriría con la madre putrefacta, envenenada por la sífilis libertina (y republi-

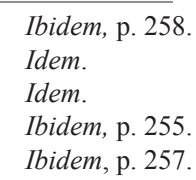


cana siguiendo a Dolmancé). Cerrar a la madre es por lo tanto un acto profiláctico que sin embargo pareciera liberar la mano (y la aguja) de la hija. Así, nota Lezra, "La furia matricida que expresa Eugénie se convierte, a su modo, en un universal paradójico, sacrificial" ${ }^{29}$. La lógica sacrificial heroica y escatológica no ha sido descompuesta todavía.

Para hacer fallar esta lógica, por un lado, Lezra se enfoca en la suspensión de la mano, en la contingencia del encuentro -ya que provee una apertura al terror republicano y la comunidad. En su errar nos preguntamos ¿a qué cuerpo irá la próxima puntada? Sujeto y objeto se hallan cosidos por una aguja fantasmática instrumental y errante al mismo tiempo. La sutura ciega pareciera ser imposible de narrativizar. Así, la aguja errante y su contacto ciego serían el veneno republicano en su contingencia radical "no-recíproca, no dialéctica y quizás inenseñable" $"$. La lógica del progreso, de la educación hacia la emancipación del hombre (y la mujer) de la ignorancia (virginidad) al conocimiento, de la emoción a la racionalidad es frustrada, desbaratada. No puede haber una "ideología del Bildung o formación cultural" ya que ocurre una "doble ceguera" que afecta tanto al "tutor como al pupilo"31. Los lectores se hayan según Lezra:

marcados como Eugénie y Madame de Mistival con las violentas trazas de la finitud, con el veneno cegador de la contingencia histórica, hallamos en el placer sobrevenido, en el placer que ocurre que los efectos de comunidad se producen, y que -con un esfuerzo, tan solo uno más- se puede construir la república ${ }^{32}$.

El veneno de la contingencia radical implica el placer cegador que permite que se congregue una comunidad republicana que incluye al lector. Esta ceguera se extiende hasta el "intervalo en que la teoría y la práctica son ciegas la una a la otra" ${ }^{33}$. El fracaso de emparejamiento entre la teoría y la práctica libertina permite la emergencia de una apertura al republicanismo y su terror. La imposible lógica reproductiva (pedagógica) de la teoría dando a luz a la práctica o viceversa permitiría pensar una violenta fundación de la politica, pero no una política ${ }^{34}$. Cerrando y abriendo, abriendo y cerrando, teoría y práctica distanciadas marcan la experiencia del terror fundacional republicano y la necesidad de "todavía un esfuerzo más".

Sin embargo, el placer errante de Eugénie no elimina el sacrificio de la madre, entonces ¿qué hacemos con este sacrificio? ¿Permiten el placer cegador de la aguja errante (impersonal y personificada) un posible deslizamiento, distanciamiento de la autoridad del padre y de la división entre amigos/enemigos? La madre sacrificada, expulsada, cerrada, no ha de serlo tan sólidamente. Esta es la lección de Lezra que no debemos olvidar. Este es el fracaso de Dolmancé y sus puntadas: ningún concepto, ninguna figura, ninguna estructura, ningún cuerpo puede

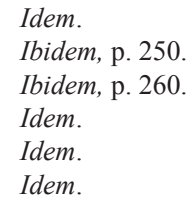

ser cerrado totalmente y así es posible que el veneno de la contingencia republicana se derrame.

\section{La madre y el veneno republicano}

Aquí, quisiera volver a uno de los textos que Lezra sigue en su lectura de Sade: "The Liberated Woman [La mujer liberada]" de Jane Gallop ${ }^{35}$. La crítica feminista tiene una relación oscilante con el texto de Sade, viéndolo en los ochenta como sexualmente liberador y luego, veinte años después, como alegoría de los límites de la figura de "la mujer liberada" y de su propia experiencia como feminista ${ }^{36}$. Gallop describe a la "mujer liberada" de los sesenta como una manera de "ser libre en maneras que mezclaba principios feministas con ideas de la revolución sexual"37. La mujer liberada "era, como los hombres, sexualmente libre"38. Dos décadas después, al releer La filosofía en el tocador, Gallop nos confiesa que reconoce en el texto a "la mujer liberada" y "lo que estaba mal en esa figura" fundada en el "deseo masculino y su modelo" 39 . Así, ella puede "ver en el ideal de Sade todo lo que la crítica feminista [le] había enseñado a ver en la revolución sexual"40. Pero no es solo en la cuestión de la teoría que la ceguera de Gallop aparece, sino también en su deseo. Gallop continúa revelando - espantada de sí misma- su vergüenza ante su práctica deseante: como mujer liberada ella siempre se había masturbado y gozado al leer este texto de Sade. La reflexión de Gallop marca la distancia entre teoría y práctica, entre lo público y lo personal, entre su propio compromiso como feminista y su goce personal. La confesión -y la escritura, o sea el pensamiento reflexivo- pareciera ser nuevo esfuerzo, uno más, de hacerlas transparentes entre sí y de ensamblarlas nuevamente. Hasta aquí, el texto de Gallop entra dentro de la narrativa pedagógica de la Ilustración, la toma de conciencia, la llegada de la razón iluminadora feminista. Pero también va más allá. El feminismo de la mujer liberada, nota Gallop, es uno que mantiene (inadvertidamente) las bases del poder masculino: la división amiga/enemiga y la aceptación final de la autoridad (patriarcal). Esta lógica es también la de la teología moderna de la soberanía que divide el mundo en la topología de amigos vs enemigos, adentro vs afuera, derechos vs no derechos. De hecho, en el texto de Sade, la madre nunca deja de ser la enemiga, como nos fuerza a observar Gallop, "Eugénie se convierte en una mujer liberada en el acto de rechazar, ofender y torturar a su madre" ${ }^{41}$. La tortura final de la madre y su sutura marca a la madre

\footnotetext{
5 J. Gallop, "The Liberated Woman”, Narrative, 13, 2, 2005, pp. 89104.

36 J. Gallop, “The Immoral Teacher”, Yale French Studies, 63, 1982, pp. 117-28. En este artículo, Gallop considera el texto de Sade como feminista por su abierto compromiso con el placer femenino y la invitación a una "posesión fugaz", así como también su aceptación y celebración del cuerpo y sus secretos, sus puntos de estremecimiento y goce y su rechazo a la familia heteronormativa reproductiva, op. cit. p. 66.

J. Gallop, “The Liberated Woman”, op. cit., p. 92, traducción propia.

38 Idem.

39 Idem.

40 Idem.

$41 \quad$ Ibidem, p. 97
} 
como lo rechazado. Gallop advierte: "La mujer liberada de Sade no es simplemente lo opuesto de la mujer «virtuosa» ella es su enemiga... La mujer liberada triunfa, la madre es sacrificada"42. Como Lezra, para Gallop es en las dudas del texto y en el placer que se puede desarmar esta lógica masculina de poder. Particularmente, ella se centra en dos indecisiones. La primera vacilación se encuentra en el epitafio de la obra. Mientras que en la primera edición dice "la madre prescribirá esta lectura a su hija", la segunda declara "la madre proscribirá esta lectura a su hija" ${ }^{43}$. El primero abre la puerta a un si hipotético: ¿pueden las madres permitir que sus hijas gocen tanto como para ordenar la lectura del libro? El segundo momento de vacilación que Gallop nota en Sade da pistas del imposible placer de la madre en el texto. Justo cuando están torturando a la madre y Eugénie ha comenzado a coserla, la hija cree entrever en los ojos de la madre la posibilidad del goce. Pero, tanto Sade como el texto dejan esta posibilidad solo como insinuación. El placer errante no está tolerado para la madre, y sin embargo el texto deja la marca de la duda, pero y si... Para Gallop, si el texto, si Sade se hubieran atrevido a permitir la emergencia de ese goce errante, de una madre gozante que prescribiera ese texto a su hija recién ahí la topología amiga/enemiga podría comenzar a deshacerse. No me interesa simplemente aquí el desarmado de esta topología interna a las mujeres (la construcción de una sororidad, homogénea y sin tensiones, y tampoco creo que eso sea lo que Gallop tiene en mente). Mas bien, veo en esto una posibilidad que el feminismo (los feminismos) y la figura de la mujer proveen para pensar/re-imaginar lo político desde otra lógica que no sea teológica, sacrificial, escatológica, y heroica, basada en la división soberana de amigos/enemigos.

En contraste, para Lezra, esta topología se deshace (o al menos se suspende) en la pérdida el cálculo racional de las puntadas (que tienen por objetivo suturar/cerrar a la madre) y que son liberadas por el goce y por lo tanto erran y deambulan conectando los cuerpos de la madre, Eugénie y posiblemente Chevalier. Los cuerpos pierden sus límites al ser atravesados por las puntadas que cruzan a través de los cuerpos. La lógica de la soberanía en tanto medios y fines pareciera detenerse. Las puntadas dejarían de ser un medio para un fin y se convertiría en su propio fin. El objetivo de matar al enemigo, de destruir el viejo sistema (o sea que la sífilis no se escape del cuerpo de la madre) pareciera ser abandonado al placer de la puntada errante cuyo único objetivo ahora es un vagar "sin ton ni son" 44 . Por lo tanto, para Lezra, una contingencia fuerte rompe la escena de la tortura. La contingencia fuerte es el terror en el sentido del concepto débil, del evento del encuentro, en este caso el encuentro entre la puntada (sin líder, sin control) y los cuerpos (que ahora pueden ser cualquiera de ellos).

Quisiera notar que Sade superpone tres experiencias sensoriales: una táctil (las puntadas, el contacto de los cuerpos, la penetración) en la que se centra el análisis de Lezra; otra auditiva (los comentarios de Chevalier,

\footnotetext{
$42 \quad$ Ibidem, p. 98.

43 Sade, op. cit. p., 179, traducción modificada.

44 J. Lezra, Materialismo, op. cit., p. 258.
}

los gritos de la madre, el aliento de instructor libertino Dolmancé) y una visual, en la que me quiero enfocar. Sade nos ofrece como lectores el espectáculo de este cuerpo tripartito, de estos cuerpos ensamblados y del orgasmo de Eugénie: nos invita a verlos en nuestra imaginación ${ }^{45}$. Para Lezra, si bien la escena teatral está claramente orquestada por Dolmancé, la aguja errante es el punctum móvil de esta escena ${ }^{46}$. La aguja gozante, ciega y errante es el detalle donde la imagen de sujeción se disuelve -aunque sea momentáneamente- donde la soberana aparece en su división y en su herida y abre una oportunidad. Pero Lezra no se queda fascinado con el halo aurático de la aguja, observa también a la madre sufriente, pero como límite a la pedagogía. La mirada de Lezra se bifurca entre el la hija y la madre, entre la contingencia y el fracaso de la pedagogía, entre el goce y el naufragio de la ilustración. Mi imaginación también se halla dividida. Entre la mano errante de Eugénie con la aguja y el cuerpo conquistado de la madre, vencido. No obstante, no quiero cegarme con el placer cegador de la aguja y dejar de mirar el cuerpo de la madre. No me puedo identificar con esta mujer. No puedo sentir su dolor. Y, sin embargo, no quiero borrar su dolor. Hacerlo me pondría en la perspectiva de Dolmancé, quien ya le había advertido a la madre que "sus gritos,... no tienen ningún propósito" ya que nadie podría oírla. Dolmancé, luego de ver esta escena, se excita sexualmente y pide suturar el ano de la madre bajo su autoridad y la doble autoridad del Monsieur de Mistival. El libro termina con Dolmancé despachando a Chevalier para que regrese a Madame de Mistival a su casa (pero prohibiéndole que tenga sexo con ella) y luego yendo a la cama con SaintAnge, Eugénie, y Agustín, un sirviente. La madre es expulsada, la prohibición de tocarla (y por lo tanto la ley del incesto) se restituye, tal como Jacques Lacan nota ${ }^{47}$. Chevalier no debe tocar a la madre, no vaya a ser que la abra de nuevo. Este es el verdadero peligro que se sutura. En los actos de Dolmancé no hay herida de la soberanía sino reafirmación de su fantasía trascendente. Ante el exilio de la madre impregnada de veneno, Dolmancé vacila ante el futuro, y busca borrar esa incertidumbre. Por eso, le prohíbe abiertamente a Chevalier que no tenga sexo con la madre suturada; no vaya a ser que se abra a la madre nuevamente, que se derrame el veneno de la contingencia republicana, y que ella pueda padecer y gozar. Es importante preguntarse cuál es la ética de lectura de esta escena ¿Cuál es su política? Todo el despliegue del orgasmo de Eugénie, toda su emancipación y liberación están enmarcados por la autoridad de Dolmancé; la cual no está herida, ni exilada y que se puede imaginar como dividida por el goce, pero unificada por la mirada.

Lezra comprende estas tensiones del texto, y para él, la salida está tanto en esa aguja errante por el deseo que se opone -podríamos agregar- a la lógica logocentrista como en la falta de lección edificante que rompe la te-

\footnotetext{
He analizado la cuestión del tacto y lo escópico, el dolor, y el placer soberano en relación a Sade y la lectura de Filosofía en el tocador en S. Peláez, "Ungrounding the Nation: Juan José Saer's Nobody Nothing Never [Nadie nada nunca]", CR: The New Centennial Review, 14.1, 2014, pp. 1-24.

46 J. Lezra, Materialism, op. cit., p. 256.

47 J. Lacan, "Kant with Sade", October, 51, 1989, p. 75.
} 
leología iluminista. Pero, ¿cuál goce? ¿Erra el goce de la aguja entre los cuerpos de Eugénie, de la madre, de Gallop, de Lezra y de nosotros? ¿Ha sido infectada la madre con ese veneno cegador cuando fue cosida? ¿Hay posibilidad de que el veneno que se creía encerrado en el cuerpo de la madre se derrame? ¿Qué abre al texto a otra lógica?, ¿el intermitente estremecimiento del goce de la madre, de la hija, de Gallop, nuestro? O ¿Es el estremecimiento de nuestro pensamiento en la falla entre teoría y práctica? La pulsión escópica de la mirada de Dolmancé sutura estas vacilaciones con su gran erección. La ética del terror que rastrea el concepto débil debe llevarnos más allá de la aguja errante y su goce, más allá de la ruina del instrumentalismo pedagógico. Bajo la mirada de Dolmancé, uno podría leer el acto gozante de Eugénie como un acto terrorista que funda una nueva comunidad en la violencia y el sacrificio de la madre. Cuando se sutura a la mirada de Dolmancé, cuando se transforma en mujer liberada, la imagen del goce errante continúa siendo profiláctica, heroica, sacrificial y escatológica. El derrame del goce de Eugénie a Gallop nos fuerza a ver, que no es en el aura del goce que está la liberación. No es en el aura de la liberación (del goce) que la república puede ser fundada. Suspendida mi mirada entre el goce y el dolor, me pregunto: ¿Se puede pensar la república más allá de la escena fundante del sacrificio y la tortura de la otra? Siguiendo las huellas de Lezra, es en el terror del encuentro contingente con estas mujeres (María, Eugénie, su madre, Gallop) que el republicanismo tiene alguna chance.

\section{Zambrano: la filosofía como mujer}

La lectura de Lezra de Zambrano nos propone otra dirección para pensar el republicanismo radical. El republicanismo de la filósofa española es un llamado a otra oportunidad, pero diferente del esfuerzo sadiano. En el texto de Sade, Dolmancé (apoyado en todas sus erecciones) es la figura de la filosofía, del conocimiento y la instrucción, nunca llega a ser Domitila. Nuevamente, Lezra no elabora las implicancias de esto, pero lo ilumina con su lectura de "Lo que le sucedió a Cervantes: Dulcinea" y marginalmente "La ambigüedad de Don Quijote" dos textos publicados en España, sueño y verdad (1965) escritos durante su exilio del franquismo ${ }^{48}$. En "Lo que le sucedió a Cervantes: Dulcinea", Zambrano narra una historia fundacional del origen de la modernidad: el momento en que Cervantes comienza a escribir El Quijote. Para Zambrano, "el rencoroso olvido" con el cual el narrador del Quijote no quiere recordar el lugar exacto de la Mancha donde comienza la novela marca, en su ausencia, el lugar del mundo, de España y del hombre en la historia y su relato ${ }^{49}$. En este comienzo cervantino, el origen del origen niega su fundamento; el hombre es lo más presente y lo más ausente. No hay dioses. Y, sin embargo, el hombre no es mera historicidad, mera realidad.

\footnotetext{
48 M. Zambrano, España, sueño y verdad, Barcelona, Edhasa, 1982. Los textos citados pertenecen a una serie en donde la filósofa discute las posiciones de Ortega y Gasset y Unamuno sobre Cervantes y España.

$49 \quad$ Ibidem, p. 52.
}

¿Qué le ha pasado a Cervantes para llegar a este punto? Dulcinea, nos responde el título del artículo, aunque el texto habla de Aldonza y solo alude silenciosamente a la primera. Para Lezra, lo que sucede es

la aparición de Aldonza, de la mujer filósofa, de la filósofa como mujer. Dulcinea/Aldonza/Zambrano equiparada a "la razón poética" y al "materialismo español", se convierte en el aparato literario suplementario que se invoca y produce cuando el pensar se adormece débil, indeciso ${ }^{50}$.

El texto de Zambrano performa la emergencia de lo que Lezra ha estado rastreando: el concepto débil. Muestra la dependencia entre el relato y el pensamiento, entre la literatura y la filosofía, entre la ficción y el concepto $^{51}$. Especialmente este "breve cuento alegórico" de Zambrano es el paradigma de la emergencia de los conceptos débiles en su abrazo abierto al entretejido de los dos discursos (ficción y filosofía) con los que construye la historia del origen de la escritura de El Quijo$t e^{52}$. Lezra lee en esta historia no solo un comentario a Cervantes y la novela sino también una alegoría de la res publica y de la Segunda República española. El texto muestra el imaginado despertar de un país en estado de autocontemplación y abstracción en tiempos del fracaso de la república y el exilio ${ }^{53}$. En ese fantaseado despertar, Lezra concibe una "figura centaura [portmanteau], ella es la condición de pensar la relación entre interés público y particular en y como momento de crisis: Dulcinea/ Aldonza/Zambrano es la triple personificación del republicanismo resistente" ${ }^{54}$. Nuevamente, para representar el republicanismo, la lectura de Lezra nos trae una figura femenina monstruosa ${ }^{55}$. Una mujer que no es una sino tres en una, una mujer centaura. En este portmanteau, las barras entre los nombres enlazan la serie al tiempo que mantienen la distancia entre ellos, permitiendo tanto la asociación como la distancia de estas tres mujeres. Ellas crean una especie de comunidad monstruosa, congregada por el terror.

\section{Aldonza y Dulcinea: estar, desprendimiento, e irradiación}

J. Lezra, Materialismo, op. cit., 314.

51 Mucho se ha dicho del estilo de Zambrano que no sigue las convenciones ni de la filosofía ni de la poesía. Su estilo busca una manera de escribir no violenta, no apropiadora, una que se distancia de la pulsión apropiadora de la filosofía y sigue lo que Zambrano llama razón poética. Cf. S. Gingerich, "Europe's Frenzy: European and Spanish Universality in María Zambrano", CR: The new Centennial Review, 8, 3, 2008, pp. 189-214 y J. Acevedo Guerra, "La razón poética. Una aproximación (María Zambrano y Heidegger)", Aurora: Papeles Del Seminario María Zambrano, 9, 2009, pp. 6-14. Para una lectura de la razón poética y "Lo que le sucedió a Cervantes: Dulcinea" cf. M. Ortega Mañez, "Desencantar a Dulcinea o Zambrano novelando a Cervantes", Aurora, 19, 2018, pp. 68-80.

$52 \quad$ Ibidem. p. 311.

53 Ibidem, p. 316.

54 Ibidem, p. 314.

55 Es interesante que la traducción de portmanteau haya sido "figura centauro" ya que nos confirma como la mujer es una figura monstruos, sin embargo, la imagen del centauro borra lo femenino. Un portmanteau es una palabra inventada que surge de la unión de otras, por ejemplo en inglés: brunch, que combina breakfast (desayuno) y lunch (almuerzo); en este caso el portmanteau es Dulcinea/Aldonza/ Zambrano. 
En "Lo que le sucedió a Cervantes: Dulcinea", el ensayo solo nombra a Aldonza, aunque alude a Dulcinea. Recordemos que Aldonza es la mujer "real" a la cual Don Quijote ha metamorfoseado en Dulcinea. En la división interna de la novela entre realidad y mundo de sueño - una división inestable de hecho- Aldonza pertenece a la primera, Dulcinea al segundo. Dulcinea es la invención e idealización consciente de Don Quijote ya que la imagina tal como lo desea marcando la distancia con Aldonza ${ }^{56}$. Zambrano pareciera operar de manera similar. Una podría decir que lo que le sucedió a Cervantes (no a Don Quijote) es cruzar la distancia entre Dulcinea y Aldonza; es ir de la imposición del estar de Aldonza a la irradiación de Dulcinea y la revelación de un horizonte invisible e internalizado. La distancia entre una y otra es fantasmática: no son la misma, o su simple reverso. Dulcinea abre en Aldonza algo que la hace no idéntica a sí misma en toda su presencia (y viceversa: Aldonza introduce algo que no es ipseidad en Dulcinea en toda su ideación). Siguiendo a Zambrano, Lezra llama la atención sobre la materialidad de Aldonza y su "indecoroso sentido de la materialidad del cuerpo" 57. Por esa materialidad, de acuerdo a Zambrano, Aldonza "estaba privada de ... la ausencia y por lo tanto no dejaba respirar" 58 . Su presencia era inevitable, apabullante, totalizante. En su encuentro con Aldonza, la libertad de Cervantes estaba coartada, no podía alejarse, pero tampoco "podía ni soñar en hacerla suya; era algo desconocido y que no sabía cómo tratar" 59 . Cervantes no podía poseerla ni siquiera en fantasías o pensamientos. Zambrano relata: “Aldonza, ... más que existir, estaba, y no había modo de acostumbrarse a esa presencia"60. Así, Aldonza disloca el estar de la existencia. Estar implica ocupar un espacio, estar en un lugar, tener cierta materialidad, en contraste, algo puede existir sin estar presente ahí. El inquietante misterio de la presencia de Aldonza es estar y no existir. Ella está ahí, presente sin existir. La suya es una presencia sin falta, sin falla. Y, sin embargo, Cervantes no escapa, sino que insiste en encontrarse con ella. Va al encuentro del hecho "y el hecho era una mujer; era algo horrible... y no sabía cómo tratarlo, qué hacer"'61. En el relato de Zambrano, la mujer, Aldonza, aparece a Cervantes en el terror del encuentro. El estar de Aldonza sin existencia no es una experiencia estética de la belleza sino del terror. El encuentro con Aldonza desata la disolución del mundo de Cervantes, ella rompe el horizonte, ese que a la distancia con su imagen organiza el mundo, da direcciones, coordenadas y sentido al mundo $^{62}$. En este punto de saturación, la presencia de Aldonza arruina todo, su encuentro fue un desencuentro que metamorfosea todo en una cadena de hechos, en una serie árida en "un el abismo del vacío: el desierto de los hechos"63. Aldonza no es un sueño, es un hecho, una pre-

\footnotetext{
M. Cervantes, Don Quijote de la Mancha, San Pablo, Alfaguara, 2004, p. 622.

sencia sin existencia y así corroe el mundo de Cervantes al tiempo que promete una verdad.

En la historia de Zambrano, Cervantes renuncia a hacer a Aldonza suya, a soñarla, y en ese gesto

acabó por sentirse libre, libre de su amor, y entrevió, al fin. Fue un desprendimiento; sintió que se le desprendía el corazón, que se quedaba en las puras entrañas como ser que no ha vivido nunca. De lejos, desde más allá de lo visible, llegó hasta él una imagen blanca, parecía la blancura, la luz misma emblanquecida para hacerse visible, una condensación de luz que tomó figura de mujer, su corazón salió a recibirla ${ }^{64}$.

Esta revelación es la irradiación de luz en una figura femenina y su llegada que es bien recibida implica el desprendimiento de Aldonza. Al desprenderse, Aldonza se aparta. Este es un acto de desapego, y Aldonza se vuelve indiferente para Cervantes. No está claro quien se desprende de quien. Pero sí que el desprenderse es un acto de generosidad y largueza. En este evento de distanciamiento, desinterés y generosidad, Zambrano relata una imagen de renacimiento, un nuevo origen no fundado ni en el sacrificio ni en la violencia. El corazón deja el cuerpo de Cervantes para ir al encuentro de esta figura irradiadora pero no es ni absorbido por la imagen (en forma redentora) ni destruido por ella (a la manera de Ícaro cuando se acerca al sol/verdad). La libertad de los hechos, de Aldonza es la liberación de Cervantes y Aldonza al mismo tiempo. Es la liberación de la presencia sin existencia, del desierto de hechos, y, lo más importante, es el evento de la escritura de Don Quijote que es una novela, un género que para Zambrano es la forma moderna literaria secular y que asume el ocaso de los dioses ${ }^{65}$. Sin embargo, para Zambrano, el fin de los dioses no es el surgimiento del racionalismo, sino es el espacio donde el racionalismo y la imagen emergen en tensión. La imagen de Dulcinea resplandece y la reconocemos en el texto, aunque ella no está más que nombrada en el título. Su resplandor marca el espacio de libertad, de desprendimiento que permite la escritura; señala el vacío desde el cual la creación es posible. Este espacio inexistente del compartir muestra el congregar de una comunidad que resiste la apropiación. Zambrano comenta: "Aquella forma blanca, que a veces se precisaba en figura de mujer" es lo que conduce a la escritura ${ }^{66}$. Esta figura de mujer intermitente, Dulcinea casi innombrada, es la que "conducía su historia, que comenzó en seguida a escribir"67. El acontecimiento de la escritura es el momento del evento y la alusión, del compartir en la ausencia, donde lo más íntimo se convierte en público. La tensión entre el título que nombra ("Lo que le sucedió a Cervantes: Dulcinea") y el texto que alude rescata la ambigüedad, evitando definiciones, respuestas claras. Al mismo tiempo, título y alusión borran el límite, el adentro del texto está afuera del texto, y el texto de Zam-

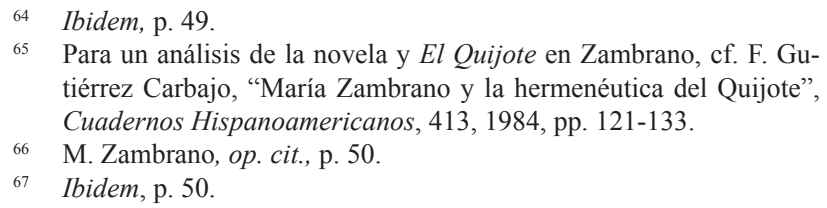

65 Para un análisis de la novela y El Quijote en Zambrano, cf. F. Gutiérrez Carbajo, "María Zambrano y la hermenéutica del Quijote", Cuadernos Hispanoamericanos, 413, 1984, pp. 121-133.

66 M. Zambrano, op. cit., p. 50.

67 Ibidem, p. 50. 
brano se abre a otras obras de Cervantes, pero también suyas.

\section{La derrota: Dulcinea y Don Quijote}

Siguiendo la alusión a Dulcinea, debemos, por lo tanto, leer el texto inmediatamente anterior a este, "La ambigüedad de Don Quijote", donde Zambrano se expande en su resplandor y su figura ${ }^{68}$. Este texto realiza una crítica de la historia como victoria. Allí, Zambrano se pregunta: “¿será Don Quijote el prototipo del héroe que no puede vencer, el prototipo del héroe que no puede ser nunca vencido?"69. Don Quijote es una novela en la cual el héroe tiene características trágicas ya que nunca puede vencer. Sin embargo, esta derrota trágica se ha modernizado. Don Quijote rompe la teleología del héroe épico, pero también el destino del héroe trágico que tiene una victoria "metahistórica" en el mundo de los dioses. El viaje de Don Quijote es dentro de la novela, un género humano, sin dioses. Él corre hacia su derrota, habiendo sido derrotado de antemano (tal como el héroe trágico), pero esta derrota no es capitulación e implica que no puede ser derrotado. Don Quijote es un hombre que siempre ha estado vencido y que al mismo tiempo nunca puede ser vencido. O sea, no hay nunca victoria absoluta, ya que tampoco hay derrota total, aun cuando solo haya derrota. Y así, la novela de Cervantes es "la fantástica historia repetida, la novelesca historia de victorias que sirven para dar lugar a la derrota, de derrotas que sirven para acusar la imposibilidad del vencimiento total" "70. Zambrano juega aquí con los dos sentidos de historia. La historia -narración de hechos, relato- y que se repite en la historia -hechos y relato- de las victorias y las derrotas ${ }^{71}$. La historia en tanto razón histórica pierde su sentido teleológico de progreso, de mejora, de medios y fines. En este punto de su argumento -cuando Don Quijote no está totalmente derrotado- Zambrano trae a la figura de Dulcinea quien "sonríe melancólica, sola, allá lejos, irónica, ella también, pues ¿acaso no amaría Dulcinea a Don Quijote?"72. Don Quijote ama a Dulcinea a la distancia, nunca viéndola o encontrándose con ella. Asimismo, tal vez Dulcinea amara a Don Quijote a la distancia. Esta posibilidad que imagina Zambrano es importante. Si se aman, su amor nunca es recíproco. Así, su amor es siempre desde ya asimétrico, mediado, solitario. El amor, en esta historia, es un sentimiento de soledad. Zambrano nos cuenta que Dulcinea sufre de melancolía ya que ha sido "reducida a esencia, a idea", a "quimera" 73. Ella que era "viviente realidad"

\footnotetext{
68 Si hubiéramos seguido el recorrido tradicional leyendo primero este, el resultado sería el mismo, ya que en este primer texto se alude al título del ensayo siguiente. En realidad, la estructura de la alusión es parte de todo texto.

69 Ibidem, p. 40.

70 Ibidem, p. 48.

71 Aquí, Zambrano discute dos lecturas de Don Quijote: una que proponía ir del relato a la historia humana (en Ortega y Gasset) y otra del relato a la religión (en Unamuno). Las dos eliminan la ambigüedad de Cervantes y el Quijote: Ortega arriba a una ética, Unamuno a un hombre cristiano inmortal.

72 Ibidem, p. 41.

73 Idem.
}

es idealizada, ella que estaba "ávida de amor viviente" no alcanza el amor ${ }^{74}$. Zambrano figura a Dulcinea como la quimera del hombre, o sea, como una monstruosidad inventada por el hombre. Este monstruo imaginado ama -quizás- pero a la distancia y sobre todo en silencio, mostrándonos solo su irónica sonrisa que pone un signo de preguntas en el amor que Don Quijote le profesa $\mathrm{y}$ que hace que sea imposible reciprocarlo. El amor interrumpe la historia como telos, ya que nos lleva a la derrota al tiempo que nos salva de la derrota absoluta. En esta historia, el hombre que crea la quimera es "el héroe" que cuando confronta a la quimera se da cuenta que "la quimera, él mismo, ángel y león, [va] hacia una muerte inconclusa" "75. La frase fragmentada y sin verbos de Zambrano marca la imposible confrontación de Don Quijote y Dulcinea (su quimera) para convertirse él mismo en monstruo y quimera que "no acab[a] de morir". Este hombre/héroe/quimera emerge en "la figura de Don Quijote, portadora del ancestral sueño de la libertad encadenada, [y] manifiesta el conflicto de ser hombre en la historia, contra ella, a través de ella y aún más allá de ella" ${ }^{\text {"76 }}$. La historia (en tanto razón histórica, causa y efecto y progresión de hechos sin dioses salvadores y redentores) no absorbe al hombre armoniosamente, ni es su simple construcción. Hay una tensión entre la historia y el hombre, quien se opone a ella, quien va más allá de la historia cuando la atraviesa (pero no entra en el campo de los dioses). Esta figura es también la del hombre español y su quimera, y sus derrotas son las de la nación (específicamente la República) española. Zambrano nos dice que esta figura/quimera

aparece revelada por su autor en el momento en que la historia de España cae sobre el hombre español, cansado ya de ella, en que por no reconocerse en ella, se va a retirar un momento después, estigmatizado, entrando en su derrota para limpiarse y purgar tanta victoria. Es signo y clave de que, sea cual fuere esta historia, no hemos tenido vocación de vencer ${ }^{77}$.

Las victorias (como las de Ortega y Gasset, Unamuno y uno podría agregar la de Franco) son el problema: lo que necesita ser purgado, evitado son los triunfos, no las derrotas ${ }^{78}$.

\section{El terror del encuentro con Dulcinea/Aldonza/ Zambrano}

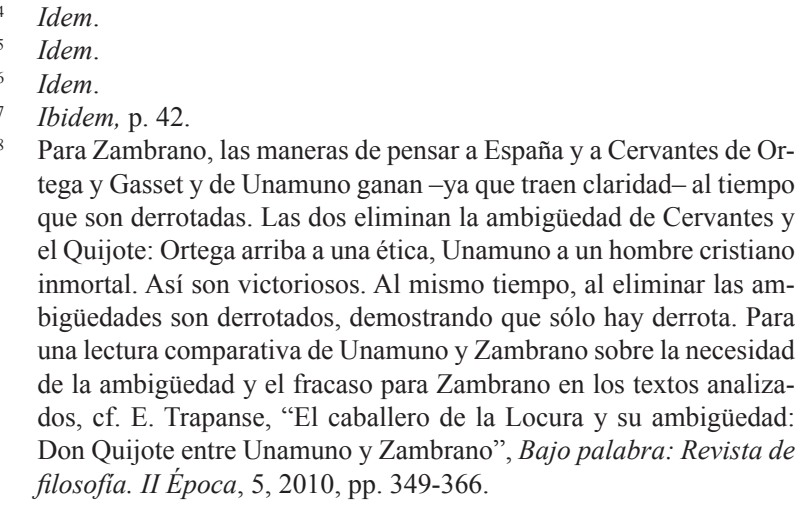
tega y Gasset y de Unamuno ganan -ya que traen claridad-al tiempo que son derrotadas. Las dos eliminan la ambigüedad de Cervantes y el Quijote: Ortega arriba a una ética, Unamuno a un hombre cristiano inmortal. Así son victoriosos. Al mismo tiempo, al eliminar las ambigüedades son derrotados, demostrando que sólo hay derrota. Para una lectura comparativa de Unamuno y Zambrano sobre la necesidad de la ambigüedad y el fracaso para Zambrano en los textos analizados, cf. E. Trapanse, "El caballero de la Locura y su ambigüedad: Don Quijote entre Unamuno y Zambrano", Bajo palabra: Revista de filosofía. II Época, 5, 2010, pp. 349-366. 
El relato/historia de Don Quijote/hombre español narrado por Zambrano nos confronta con el terror del encuentro con Dulcinea/Aldonza/Zambrano relatado por Lezra. (Recordemos que las barras identifican y separan al mismo tiempo). Ya hemos explorado las diferencias entre Dulcinea y Aldonza. La imagen de Dulcinea no es complementaria, o simple opuesto ideal de Aldonza. Es un suplemento. Ninguna existe, las dos están presentes, pero una con una presencia abrumadora y totalizante y la otra con una presencia intermitente y liberadora que genera el vacío en la totalidad y que permite la creación. Lo que le sucedió a Zambrano, lo que la saca del resguardo de su interioridad es el "toque íntimo, privado" de Aldonza/Dulcinea ${ }^{79}$. Con ese toque, Zambrano se une a ellas. La filósofa/narradora y su razón poética generan una "cadena de sustituciones e identificaciones [que] no solo lleva del cuerpo ideal de Dulcinea al cuerpo público de Aldonza, sino que asimismo continúa hasta el propio cuerpo de Zambrano"80. El monstruo va asociando a la ideal Dulcinea, al cuerpo de Aldonza y al cuerpo de Zambrano. Esta monstruosa trinidad no promete redención o juicio final. No es la versión femenina del Padre, Hijo y Espíritu Santo. Es una quimera de tres cabezas, una mujer monstruosa formada por la agregación de tres con diferentes densidades, materialidades, y opacidades. El encuentro con ella/s incita terror. Para Lezra, la cadena de equivalencias organizada por estas tres mujeres revela la emergencia de la res publica. En la obra de Zambrano, "res y res publica surgen a una como un par de conceptos turbulentos, no dialécticos, débiles" que se conectan "en el portmanteau, que resulta ser la personificación literaria (si es que cabe llamarla así) de Dulcinea/ Aldonza/ Zambrano"81. Para Lezra esta figura tripartita puede tocar al lector en la medida en que, en tanto figura literaria, es una cosa pública ${ }^{82}$. Por un lado, esta monstruosa trinidad, esta cosa, es la más íntima, por el otro, se rebalsa y derrama a lo público. El pasaje "desde la intimidad de la res hasta la res publica" que personifica políticamente al sujeto privado se da a través de "la figura de la alusión" La alusión implica un compartir entre la persona que realiza la alusión y la que intenta decodificarla. La alusión siempre crea una comunidad de sentido, de conocimiento, de referencias que circulan en la esfera pública (aunque éstas nunca son transparentes). El pensamiento de Zambrano es resistente y republicano en tanto la quimera de tres cabezas piensa a destiempo a Cervantes aludiendo a la República. Dulcinea/Aldonza/Zambrano entra no en el tiempo mítico, sino a "deshora", siempre "en el momento equivocado, en un tiempo equivocado" El republicanismo resistente, siguiendo a Lezra, aparece como Dulcinea/ Aldonza/Zambrano siempre a destiempo y tocándonos en la forma más íntima y más pública a la vez. La república, por lo tanto, nunca está más allá, afuera, en el futuro como en la invocación sadiana a un esfuerzo más, sino que es lo que es más privado que se

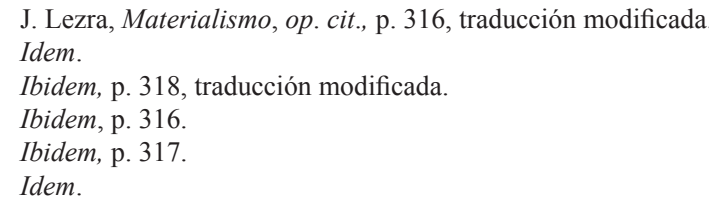

derrama a lo público siempre de manera inoportuna ${ }^{85}$. En esta argumentación, Lezra nota en Zambrano una disposición melancólica que nombra la falta de objeto-república, similar en ese sentido al goce cegador, pero que también puede quedarse peligrosamente suspendida en la inacción ${ }^{86}$. Pero, cabe preguntarse ¿cuán cerca y cuán lejos está Eugénie de Dulcinea/Aldonza/Zambrano? ¿Cuál es la diferencia entre el toque de la aguja errante (pero también torturadora) y el toque de la alusión y figuración literaria en Zambrano? ¿No es la aguja errante otra figuración literaria que nos toca? ¿Es la escena de la tortura de la madre una simple figuración alegórica? ¿Cuál es la importancia de que estas mujeres monstruosas figuren lo republicano? ¿La figuran de igual manera?

\section{El terror del encuentro y la lógica femenina}

La lectura del texto de Sade y el goce errante de Eugénie nos acercan a la república en tanto podemos pensar en su fracaso y falla los límites de ciertos movimientos de liberación, como argumentase Gallop para cierto feminismo y el movimiento de liberación femenino, pero también de otros movimientos emancipatorios como los de los años 70 en Latinoamérica. La liberación de Eugénie, como argumenté, todavía sigue engravada por la narrativa heroica y sacrificial de la jerarquía patriarcal logocéntrica. Nos alienta a un esfuerzo más si queremos ser republicanos. Este fracaso está marcado con un encore (otra vez), otro esfuerzo del republicanismo moderno que pareciera definir la república como futuro, como objetivo a conseguir con sólo un esfuerzo más. Lezra sigue este imperativo del pensamiento y nos guía a Zambrano. En ella, también podemos leer un fracaso, una derrota, esta vez la de la Segunda República y de España. Este fracaso nos lleva a otro significado. Aquí no hay sacrificio, ni héroe, ni victoria. La derrota es la que organiza lo común, el compartir, pero no con la lógica catastrófica del desastre fundador. Sade condice a una ética que impulsa una política de la victoria prometida, a una república siempre en el futuro. Zambrano, por el contrario, sugiere una ética de la derrota que está en el origen, pero no lleva a una política de protección y expulsión preventiva. Como Don Quijote, esta derrota nunca puede ser victoriosa, pero por eso nunca puede ser totalmente vencida. Esta ética se desvía del relato político del origen heroico y sacrificial ${ }^{87}$. Con Zambrano la mera cuestión de a quién se debe sacrificar para que la república viva/renazca otra vez pierde peso y sentido. Y, sin embargo, esto no significa un abandono, pero, al contrario, una libertad para pensar dentro y por el fracaso. La derrota que no puede ser derrotada, da forma a la ética de terror que Lezra nos invita a seguir, pero también nos lleva a la piedad en la derrota.

En nuestra lectura rastreamos la figura de ciertas mujeres monstruosas. Lezra no profundiza en el hecho de que son mujeres una y otra vez las que corroen la supuesta fortaleza de los conceptos, debilitándolos,

\footnotetext{
Ibidem. p. 324.

86 J. Lezra, República, op. cit., p. 325.

87 Para una lectura de Zambrano que analiza como la filósofa se aleja de la soberanía schmittiana hacia una comunidad afectiva no sacrificial, cf. C. Varón González, op. cit., p. 180.
} 
abriéndolos, volviéndolos porosos. Estas mujeres no pueden ser meramente identificadas, particularizadas y universalizadas (como María) en el concepto de Mujer universal. Por eso encontrarse con ellas (y con María) es tan corrosivo y aterrorizador. La estructura del evento republicano, sugiero, es femenina en términos de las fórmulas de sexuación de Lacan, quien distingue dos lógicas discursivas, dos formas de enfrentar lo simbólico: la masculina y la femenina. Esta división no se basa en la biología sino en la diferencia sexual y como una (no) se relaciona con ella ${ }^{88}$. La diferencia sexual no es una lógica binaria de oposición o complementariedad, similitud y diferencia. El lado masculino busca suturar la inconsistencia y mantener el ideal de una lógica totalizante fundada en el Otro; puede admitir que la totalidad no existe, pero igual la pretende. Se basa en la excepción y el universalismo de la función fálica (la castración). En el lado femenino no hay excepción, no hay quien no esté marcada por la función fálica (la castración), y al mismo tiempo no todas están bajo la función fálica y justamente por eso, puede ver su falacia. El lado masculino piensa en términos de una estructura sostenida en la fantasía del gran Otro, mientras que el lado femenino sabe que, al final de cuentas, no hay sistema, no hay gran Otro que pueda fundar/cerrar el lazo afectivo-social y, por ende, lo mantiene abierto, poroso. Así, el lado femenino habita en la incompletitud, el no-todo, no por ser incompleto sino porque no cierra. Allí, la topología adentro y afuera se deshace. Este lado reside en la inconsistencia, interroga la sutura y mantiene la apertura y el no-todo. El lado masculino cierra los conceptos, los sutura. Mientras que el lado femenino los erosiona y debilita. La lógica masculina es la de la excepción soberana, mientras que la femenina es la de una soberanía débil, dividida. El lado masculino calcula el encuentro para evitar el terror, mientras que el lado femenino sabe que es imposible calcularlo y se abre al terror del encuentro. Por eso, el lado femenino es siempre figura monstruosa, erosionando los límites del adentro y afuera, de la dualidad en sus diferentes manifestaciones. El terror del encuentro con el otro/ la otra viene con Lezra en la figura de estas mujeres, las cuales, una a una y a su manera, interfieren con él, conmigo, a las que nunca puede ni puedo apropiar totalmente o encerrar en sólidos conceptos. He tratado de hacer honor a esta ética del terror y a la derrota rastreando derrotas y al "dividir, siempre dividir". Materialismo Salvaje es pues, una invitación a confrontar nuestro propio desprendimiento de los otros, en la intimidad de la res publica de la lectura y la escritura y confrontando el terror (y la piedad) del encuentro.

\section{Bibliografía}

Acevedo Guerra, J., “La razón poética. Una aproximación (María Zambrano y Heidegger)”, Aurora: Papeles Del Seminario María Zambrano, 9, 2009, pp. 6-14.

Cervantes, M., Don Quijote de la Mancha, San Pablo, Alfaguara, 2004.

Lacan, J., "Kant with Sade", October, 51, 1989, 55-75.

Lezra, J., Materialismo Salvaje. La ética del terror y la república moderna, trad. Rodríguez Fernández, J., Madrid, Siglo XXI, 2012.

-, República Salvaje: de la naturaleza de las cosas, Santiago de Chile, Macul, 2019.

Llevadot, L., "No somos histéricas, somos históricas. Žižek, Butler y el problema de la diferencia sexual”, Res Publica. Revista de Historia de las Ideas Politicas, 23,3, 2020, pp. 343-354.

Gallop, J., "The Immoral Teacher", Yale French Studies, 63, 1982, pp. 117-28.

-, “The Liberated Woman”, Narrative, 13, 2, 2005, pp. 89-104.

Gingerich, S. "Europe's Frenzy: European and Spanish Universality in María Zambrano", CR: The new Centennial Review, 8, 3, 2008, pp.189-214.

Gutiérrez Carbajo, F., "María Zambrano y la hermenéutica del Quijote”, Cuadernos Hispanoamericanos, núm. 413 (noviembre 1984), pp. 121-133, versión electrónica, Biblioteca Virtual Miguel de Cervantes, Alicante, 2015, http://www.cervantesvirtual. com/nd/ark:/59851/bmcbp200.

Ortega Mañez, M., "Desencantar a Dulcinea o Zambrano novelando a Cervantes", Aurora, 19 2018, pp. 68-80

Sade, M. de., Justine, Philosophy in the Bedroom \& Other Writings, comp. y trad. R. Seaver y A. Wainhouse, New York, Grove Press, 1990.

Peláez, S., "Ungrounding the Nation: Juan José Saer's Nobody Nothing Never [Nadie nada nunca]" CR: The New Centennial Review, 14,1, 2014, pp. 1-24.

Trapanse, E., "El caballero de la Locura y su ambigüedad: Don Quijote entre Unamuno y Zambrano", Bajo palabra: Revista de filosofía. II Época, 5, 2010, pp.349-366.

Varón González, C., "La niña y el soberano, sacrificio y poder en Ortega y Zambrano”, Revista de Estudios Hispánicos, 54, 2020, pp. 159-184.

Zambrano, M., España, sueño y verdad, Barcelona, Edhasa, 1982.

Žižek, S., Sex and the Failed Absolute, Londres, Bloomsbury, 2020.

\footnotetext{
Para una lectura del reciente debate sobre la diferencia sexual cf. L. Llevadot, "No somos histéricas, somos históricas. Žižek, Butler y el problema de la diferencia sexual", Res Publica. Revista de Historia de las Ideas Políticas, 23, 3, 2020, pp. 343-354. Para una aproximación
}

a las fórmulas lacanianas de sexuación, cf. S. Žižek, Sex and the Failed Absolute, Londres, Bloomsbury, 2020. Para una lectura que identifica la razón poética de Zambrano con lo femenino en tanto dislocación de la diferencia de género cf. C. Varón González, op. cit. pp. $175,177,180$. 